\title{
Peculiarities of Growth, Development of the Bowler - Salsola arbuscula Pall in the Conditions of the Carnabchul Gypsum Desert
}

\author{
Boboyeve Adiba Saidaliyevna* and Rabimmov Abdulla
}

Scientific Research Institute of Desert Ecology, Uzbekistan

*Corresponding author

\section{A B S T R A C T}

\section{Ke ywords \\ Carnabchul, Gypsum desert, Salsola arbuscula pall, Degraded pastures, Peganum harmala and Agrobiocenosis \\ Article Info \\ Accepted: \\ 07 May 2019 \\ Available Online: \\ 10 June 2019}

\section{Introduction}

The desert Karnabchul covers an area of more than 500,000 hectares and is one of the largest breeding regions of Karakul sheep and goats. Pastures of Karnabchul belong to the semishrub-ephemeral type and in the vegetation cover the main defect is wormwood Artemisia diffuse Krasch. Due to overgrazing, at present, most of the pastures of Karnabchul are degraded, pastures are overgrown with non-eaten and poorly eaten plants, such as Peganum harmala L, Psoralea drupaceous
Bge, Delphinium semibarbatum, Ceratocephalis falcatus Pers., Hordeum lepormeph and etc.

To improve and increase the productivity of degraded pastures, a number of promising phytomeliorants are recommended (Rabbimov and Mukhimov, 2012; Rabbimov et al., 2015; Akhmedov et al., 2009; Rabbimov, 2015; Khamraeva, 2018). However, the wild-growing flora of arid zones is a powerful source for the introduction into the culture of species of food 
plants that are resistant to stress factors of the desert environment.

Boyalov associations can be found on pastures of Muynak, Kungrad districts of Karakalpakstan, Karakul districts of Bukhara region. The leaves and young shoots of the bull are well eaten by sheep in the fall. The nutritious bird belongs to the plants of average quality. According to $\mathrm{Li}$ and Berkovich (1970), in the spring there is a lot of raw protein $(19.8 \%)$ and protein $(13.4 \%)$ in spring. Drought resistance, resistance to grazing and good forage qualities of the prerequisites for introducing it into culture in the conditions of the Karnabchul desert.

\section{Materials and Methods}

The aim of our research is to study the growth and development, the formation of the crop of fodder biomass and the survival of the Salsola arbuscula Pall individuals in the conditions of the wormwood-ephemeral desert Karnabchul due to the increase in fodder productivity of degraded pastures. Based on this, the objectives of the research were:

-study of the growth and development of the plant of a baby in the new growing conditions;

-study of the survival rate of individuals;

-study of the forage productivity of a kid in the culture;

-study the features of the formation of the root system.

The seeds of the bobtail were collected from a wild-growing population growing in the Muynak district of the Republic of Karakalpakstan. Sowing of seeds was carried out on the plowed plot of Karnabchul in December 2015 with embedding to a depth of $0.5-1.0 \mathrm{~cm}$. Studies on the biological study of the little boy were conducted in 2016-2018 in the wormwood-ephemeral desert Karnabchul
(Karnab hospital) Research Institute of Karakul and the desert ecology.

Phenological observations were carried out according to the method of Beideman (1960). The number and survival rate of seedlings and adult plants were determined by continuous counting them on the plots twice during the growing season (spring and autumn). Plant growth dynamics was studied on 25 plants monthly. The crop of the aerial phytomass was determined by continuous cutting of plants at a height of $5-8 \mathrm{~cm}$ from the soil surface. The nature of growth and formation of root systems was studied by the trench method (Shalyt, 1960). Static data processing was carried out according to the standard technique (Dospekhov, 1979).

\section{Features of seasonal development}

The emergence of shoots was noted in early April 2016. Boyalish belongs to plants of spring-summer and autumn vegetation. In nature, the vegetative period of the bull begins in the second decade of March. In April, it grows intensively and forms numerous shoots. At the beginning of May the little boy starts the budding phase. Flowering occurs at the end of May and lasts 15-20 days. With the onset of summer hot and dry climate (June-July), the little girl loses part of the leaves and is in summer rest. Fetus hawking occurs in September and October. Fruit ripening was noted at the end of October, at the beginning of November (Lee, 1983).

In terms of culture in Karnabchul, the emergence of shoots begins in mid-March. At the end of April and in the beginning of May, it starts the phase of budding. In late May, begins to bloom. In July, it loses part of the leaves and is in a state of summer rest until September. In September, the phase of fruiting was marked, and in November, the 
ripening and shedding of fruits (Fig. 1). In the first year of life, $75-80 \%$ of the plants had full-grown seeds. The vegetation period was 235 days. It should be noted that in natural conditions the boy enters the generative phase at the age of 5-6 years (Lee, 1983).

In the second year of the growing season (2017) spring growth of the boylych was recorded in mid-March. The phase of budding started in mid-May. In early July, some leaves fall off and enter summer rest. In the middle of August, the boyish appeared new leaves, he enters the flowering phase. The phase of fruiting and seed ripening is observed in midOctober and early November. The growing season lasted for 230 days. In the extremely dry 2018 (a total of $72 \mathrm{~mm}$ of precipitation fell, according to average long-term data, 162 $\mathrm{mm}$ ), the beginning of spring regrowth of the little girl was recorded in early March. Scattering of leaves occurred in the month of June. Flowering occurred in September, ripening in late October, early November. The vegetative period of the hawker in the arid 2018 was 225 days.

\section{Survival of individuals}

In the first year of life, the survival rate for shoots of the Little Boy was 50\%, and for keyreuk (Salsola orientalis G. Gmell) it was noticeably higher $-74.8 \%$. In the second year of life, there was also a slight decrease in the number of plants in the plots: in the hawk, $44.0 \%$, and in the Keireuka, $64.0 \%$ of the initial density of the plants in the accounting plots. In the third year of life, the density of standing plants stabilized, the loss of plants in both species was not observed. Thus, under the conditions of Karnabchul in culture, the survival rate of the hawkish individuals at the end of 3 years of life was $44 \%$, and in Keireuka, $64.0 \%$ (Table 1). Some high survival rates of Keyreuk individuals are explained by the fact that the Keireuk belongs to the real gypsophilia and it has been cultivated in Karnabchul for a long time, the gypsum desert Karnabchul for him is the ecological optimum, and the little boy is tested in these conditions for the first time. There is some advantage of the hawker on plant growth. At the end of the first year of life, the height of the plants of the baby haul was $31.0 \mathrm{~cm}$, and at the Keyreuk it was 27.9 $\mathrm{cm}$. In the second year of life, 58.2 and 54.1 $\mathrm{cm}$, respectively. In the third (2018) year of life, the height of the plants was slightly lower compared to last year, it was $51.6 \mathrm{~cm}$ for the shepherd and $48.3 \mathrm{~cm}$ for the keireuk. This, in our opinion, is related to the climatic conditions of the arid 2018.

The number of shoots on one bush in the first year of life at the Little Hawthorn averaged 5.6, and in Keireuka, 4.3. In the second year of life, respectively: 13.1 and 11.7 pcs. In the extremely dry 2018 year, in contrast to the Keireuka, the bush of the young hawk formed an average of 35.6 pcs shortened generative shoots, while in Keireuk, the number of generative shoots averaged 33.4. Accounting of the yields of above-ground plant phytomass showed that under the conditions of Karnabchul the little bull can form a forage mass that is 2-3 times greater than the yield of natural pastures. Thus, in the first year of life, the harvest of the above-ground phytomass of the Little Boy was 5.1 c/ha, keireuka - 4.2 $\mathrm{c} / \mathrm{ha}$, while the yield of natural pastures was $3.2 \mathrm{c} / \mathrm{ha}$. In the second year of life, the crop of dry aboveground phytomass was 14.8, 18.3 centners per hectare, while the yield of natural pastures was 3.7 centners per hectare.

In the arid year of 2018, the harvest of the aboveground phytomass of the boyleh was 14.6 centers per hectare, while the keireuka produced 15.4 centners per hectare when the yield of natural pastures was 2.1 centners per hectare. 
Features of the formation of the root system

Information about the structure of root systems, the nature of their growth and development, depending on environmental conditions, is one of the important scientific prerequisites for introducing valuable fodder plants into culture, selecting them to create the desired types of artificial phytocenoses in arid zones. In this regard, special attention was paid to studies on the root systems of such promising phytomeliorants as Haloxylon aphyllum, Salsola paletzkiana, Kochia prostrata, Salsola orientalis, Artemisia diffusa, Ceratoides ewersmanniana and others.

As a result of these studies, it was found that the root systems of the shrubs and semishrubs discussed above are used to fundamentally improve the pastures of the arid zone of Central Asia, mostly of a universal type with a clear tendency to develop in the vertical direction.

Table.1 Survival rate of the Hawkish and Keireuka individuals in the gypsum desert Carnachchul

\begin{tabular}{|c|c|c|c|c|c|c|}
\hline \multirow{2}{*}{$\begin{array}{c}\text { Type of } \\
\text { plant }\end{array}$} & \multicolumn{6}{|c|}{ The number of plants on the plots, pcs } \\
\cline { 2 - 7 } & $\begin{array}{c}\text { The first y } \\
(2016) \mathrm{y}\end{array}$ & $\%$ & $\begin{array}{c}\text { The second y } \\
(2017) \mathrm{y}\end{array}$ & $\%$ & $\begin{array}{c}\text { The third y } \\
(2018) \mathrm{y}\end{array}$ & $\%$ \\
\hline bayalysh & $90,6 \pm 7,8$ & 100 & $45,3 \pm 5,8$ & 50,0 & $45,0 \pm 2,9$ & 50,0 \\
\hline keireuk & $87,6 \pm 9,1$ & 100 & $65,6 \pm 6,9$ & 74,8 & $65,1 \pm 4,2$ & 64,0 \\
\hline
\end{tabular}

Such as rainwater, capillary, condensation, as well as groundwater. It is an important feature of the environment (Shamsutdinov, 1975). In the first year of life, on the medium loamy gray Serozem of Karnabchul, the penetration depth of the main root of the shepherd was 80 $\mathrm{cm}$. More than 10 lateral roots were found on the arable layer, spreading horizontally to a distance of $10-15 \mathrm{~cm}$. In the second year, the main roots went deeper to $150 \mathrm{~cm}$, and side adventitious roots in a layer of $0-50 \mathrm{~cm}$ in the horizontal direction spread up to $60-70 \mathrm{~cm}$. The number of horizontal roots reached 21 pieces.

In conclusion, thus, the boy in the first year of life formed the root system, the depth of penetration of which exceeds the height of its above-ground part by 2.5 times, in the second year of life by 2.6 times, and in the third year of life by 4.3 times. On the lateral roots of different orders there are many root hairs, especially a lot of them on the roots, located in layers of silt and sand, which are distinguished by high humidity. Rapid growth and the formation of a powerful root system are crucial in the rational use of water-mineral resources of the environment and the formation of high yields of fodder and seed products.

Thus, the results of the research indicate that the little boy has an adaptive potential in gypsum desert conditions; it can be successfully grown as a component in creating artificial multicomponent and highyielding pasture agrobiocenosis in degraded areas of the Karnabchul desert.

\section{References}

Li A., BerkovichV. The chemical composition of the main dominant plants of the South-Western Kizilkum and its changes by seasons // Materials on the structural and functional features of useful wild plants of Uzbekistan. 
Tashkent, 1970. Pp. 163-170.

Rabbimov A., Mukimov T.X., Bozorov A. Advice on improving livestock grazing. Samarkand, 2015. p. 55.

Akhmedov., Yusupov S., Rabbimov A. Rational use of Kizilkum pastures. Tashkent, 2009. p.123.

Rabbimov A., Mukimov T. Kh. Recommendations for the rational use and productivity of desert pastures. Tashkent, 2012. P.48.

Khamraev G.U. Agro technical bases of introduction to the culture of perennial species of the genus Atriplex L. In the conditions of the wormwoodephemeral desert Karnabchul. (PhD). Samarkand, 2018.p.22.

\section{How to cite this article:}

Boboyeve Adiba Saidaliyevna and Rabimmov Abdulla. 2019. Peculiarities of Growth, Development of the Bowler - Salsola arbuscula Pall in the Conditions of the Carnabchul Gypsum Desert. Int.J.Curr.Microbiol.App.Sci. 8(06): 773-777.

doi: https://doi.org/10.20546/ijcmas.2019.806.092 